\title{
Sechelleptus arborivagus sp. nov., a new arboreal spirostreptid millipede (Diplopoda, Spirostreptidae) endemic to Mayotte Island (Comoros Archipelago), Indian Ocean
}

\author{
Didier VANDENSPIEGEL ${ }^{1, *}$, Arnaud HENRARD ${ }^{2} \&$ Aurore MATHYS ${ }^{3}$ \\ ${ }^{1,2,3}$ Biological Collection and Data Management Unit, \\ Royal Museum for Central Africa, Tervuren, Belgium. \\ ${ }^{3}$ Royal Belgian Institute of Natural Sciences, Vautierstraat 29, B-1000 Brussels, Belgium. \\ ${ }^{*}$ Corresponding author: didier.van.den.spiegel@africamuseum.be \\ ${ }^{2}$ Email: arnaud.henrard@africamuseum.be \\ ${ }^{3}$ Email: aurore.mathys@africamuseum.be \\ ${ }^{1}$ urn:lsid:zoobank.org:author:CE8C3D01-28AD-43F7-9D4F-04802E68CB1A \\ ${ }^{2}$ urn:lsid:zoobank.org:author:E1B02E6E-D91C-43FE-8D8C-CD102EFEE3B4 \\ ${ }^{3}$ urn:lsid:zoobank.org:author:0C 719566-2901-471D-B88E-CE3EBB476172
}

\begin{abstract}
A new millipede species of the genus Sechelleptus Mauriès, 1980 is described and illustrated from Mayotte Island, Indian Ocean. This new species, S. arborivagus sp. nov., found on trees, looks particularly similar to the sympatric $S$. variabilis VandenSpiegel \& Golovatch, 2007, but is much larger and has a very different ecological behavior. Phylogenetic analyses based on a concatenated dataset of the COI and 16S rRNA genes and including nine species of Spirostreptidae (including Sechelleptus, Doratogonus Attems, 1914, Bicoxidens Attems, 1928 and Spirostreptus Brandt, 1833), strongly support the monophyly of Sechelleptus. Despite the similarity of their genitalia, the molecular analyses also reveal a clear-cut genetic divergence between $S$. arborivagus sp. nov. and $S$. variabilis $22.55 \%$ for COI and $6.63 \%$ for $16 \mathrm{SrRNA}$ ) and further suggest the presence of a higher diversity within the genus Sechelleptus on Mayotte.
\end{abstract}

Keywords. Comoros archipelagos, new species, phylogeny, taxonomy.

VandenSpiegel D., Henrard A. \& Mathys A. 2021. Sechelleptus arborivagus sp. nov., a new arboreal spirostreptid millipede (Diplopoda, Spirostreptidae) endemic to Mayotte Island (Comoros Archipelago), Indian Ocean. European Journal of Taxonomy 755: 1-21. https://doi.org/10.5852/ejt.2021.755.1395

\section{Introduction}

The genus Sechelleptus Mauriès, 1980, a senior synonym of Rubanostreptus Krabbe, 1982 (Jeekel 1999), was erected by Mauriès (1980) to reassign Iulus seychellarum originally described by Desjardins (1835) from a specimen collected in the Seychelles. The genus had been considered as monotypic until the extension of the generic concept by Golovatch \& Korsós (1992) to include a large group of spirostreptids from Madagascar. First supposed to be restricted to Madagascar and some adjacent islands, the genus 
appears to have a wider distribution ranging from East Africa to Madagascar and species of the same genus have been observed in Tanzania (Enghoff et al. 2016), Mauritius and Zanzibar (Jeekel 1999), and the Comoros (VandenSpiegel \& Golovatch 2007). In the latter study, the authors described a new species of Sechelleptus, i.e., S. variabilis VandenSpiegel \& Golovatch, 2007, and mentioned the presence of another putative congener. However, they were unable to assign the single female specimen found to a formal species. Based on its appearance and peripheral characters, the unknown female was at least assigned to the genus Sechelleptus (VandenSpiegel \& Golovatch 2007).

In 2019, at the initiative of DEAL Mayotte, a new visit was organized to Mayotte. The visit was effectuated in November, during the rainy season, and allowed to collect, for the first time, two mature males of a large spirostreptid, corresponding to the unknown females mentioned in VandenSpiegel \& Golovatch (2007). The study of the newly collected material shows that this species and S. variabilis are morphologically quite similar. At the first glance, even the gonopods of the large specie look like a giant form of those of $S$. variabilis. Nevertheless, a closer observation of the specimens reveals morphological differences, which are corroborated by a molecular study. In this paper, a morphological description of the new species is provided and its phylogenetic affinities are discussed.

\section{Material and methods}

\section{Taxon sampling and morphological examination}

This study is mainly based on material from Mayotte Island, collected in 2019 by the first and third authors. Some additional samples were obtained from the Royal Museum for Central Africa (RMCA), Tervuren, Belgium.

All samples are stored in 70\% ethanol. Specimens for scanning electron microscopy were air-dried, mounted on aluminum stubs, coated with gold and studied using a JEOL JSM-6480LV scanning electron microscope.

The terminology used to describe the gonopod structures follows that of Hoffman (2008). All measurements are in mm unless otherwise indicated.

\section{Abbreviations}

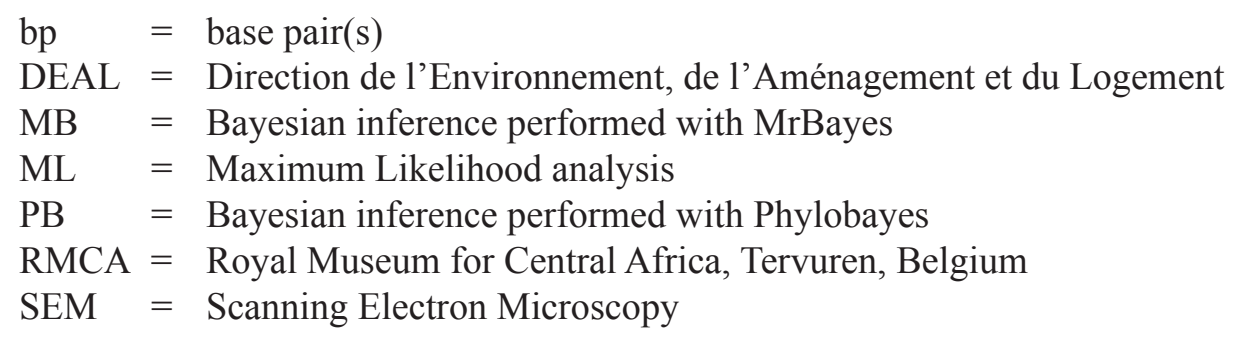

\section{DNA extraction, amplification and sequencing}

A few legs of seven freshly collected diplopod specimens, plus one older sample from the RMCA collection, all from Mayotte, were detached for molecular analysis (Table 1). The DNA of each sample was extracted with a Macherey-Nagel NucleoSpin tissue kit, slightly adapted from the manufacturer's protocol. Partial fragments of two mitochondrial markers, the cytochrome c oxidase subunit I (COI) and the large subunit ribosomal RNA (16S rRNA), were amplified with polymerase chain reactions (PCRs) using the primers displayed in Appendix 1. All amplifications were performed in a $20 \mu \mathrm{L}$ reaction mixture containing $2 \mu \mathrm{L}$ of extracted DNA (regardless of initial concentrations), $2 \mu \mathrm{L}$ of $10 \mathrm{X}$ buffer, $0.5 \mathrm{mM} \mathrm{MgCl} 2,0.2 \mathrm{mM}$ dNTP, $0.8 \mu \mathrm{M}$ of each primer, and 0.02 units/ $\mu \mathrm{L}$ of PlatinumTM Taq DNA Polymerase (Invitrogen ${ }^{\mathrm{TM}}$, Waltham, MA, USA). PCR conditions comprised an initial denaturation at 
Table 1. List of the sequenced specimens of Sechelleptus Mauriès, 1980, with DNA sample ID, Type specimen $(\mathrm{Ht}=$ Holotype; $\mathrm{Pt}=$ Paratype; $\mathrm{NT}=$ non type $)$, Museum and collection information, sex stage $(\mathrm{F}=$ female; $\mathrm{M}=$ male; $\mathrm{SubF}=$ sub-adult female $)$ and GenBank accession number for $\mathrm{COI}$ and $16 \mathrm{~S}$ rRNA markers.

\begin{tabular}{|c|c|c|c|c|c|c|c|c|}
\hline $\begin{array}{l}\text { Sample } \\
\text { ID }\end{array}$ & Species & Type & Specimen Ref. & Locality & Date & $\mathbf{M} / \mathbf{F}$ & COI & $16 S$ \\
\hline DB1 & S. arborivagus sp. nov. & $N T$ & BE_RMCA_MYR.Dip.17917 & Mt Benara & 2004 & $\mathrm{~F}$ & - & MW148621 \\
\hline DB2 & S. arborivagus sp. nov. & $H t$ & BE_RMCA_MYR.Dip.22874 & Mt Tchaourembo & 2019 & M & MW168813 & MW148622 \\
\hline DB3 & S. arborivagus sp. nov. & $P t$ & BE_RMCA_MYR.Dip.22875 & Mt Tchaourembo & 2019 & $\mathrm{~F}$ & MW168814 & MW148623 \\
\hline DB4 & S. arborivagus sp. nov. & $P t$ & BE_RMCA_MYR.Dip.22876 & Mt Tchaourembo & 2019 & F & MW168815 & MW148624 \\
\hline DS1 & S. variabilis & $N T$ & BE_RMCA_MYR.Dip.22877 & Mapouera & 2019 & M & MW168816 & MW148625 \\
\hline DS2 & S. variabilis & $N T$ & BE_RMCA_MYR.Dip.22878 & Merereni & 2019 & $\mathrm{~F}$ & MW168817 & MW148626 \\
\hline DS3 & S. variabilis & $N T$ & BE_RMCA_MYR.Dip.22879 & Merereni & 2019 & F & MW168818 & MW148627 \\
\hline DU1 & Sechelleptus sp. & $N T$ & BE_RMCA_MYR.Dip.22880 & Mt Combani & 2019 & SubF & MW168819 & MW148628 \\
\hline
\end{tabular}

$94^{\circ} \mathrm{C}$ for 3 min followed by 35 cycles with, per cycle, a denaturation at $94^{\circ} \mathrm{C}$ for $45 \mathrm{~s}$ followed by an annealing step of $45 \mathrm{~s}$ at $48^{\circ} \mathrm{C}$ and an extension step at $72^{\circ} \mathrm{C}(1 \mathrm{~min})$ and with a final extension at $72^{\circ} \mathrm{C}$ for $10 \mathrm{~min}$ followed by $10 \mathrm{~min}$ at $4^{\circ} \mathrm{C}$. PCR products (and negative controls) were checked on a $1.5 \%$ agarose gel containing $0.03 \%$ of MidoriGreenTM Direct (NIPPON Genetics Europe, Dueren, Germany) using a UV transilluminator. Positive amplifications were purified using the ExoSAP-ITTM protocol (following manufacturer's instructions) and then sequenced in both directions, using the same couples of primers (0.05 mM each), by Macrogen Inc. (Seoul, South Korea). The sequences were checked using Geneious R11 (Biomatters Ltd., Auckland, New Zealand): paired bi-directional strands were trimmed, assembled, edited and consensus sequences were extracted for each specimen and each DNA marker. The COI sequences obtained for the three specimens of Sechelleptus arborivagus sp. nov. (DB2, DB3 and DB4) were further manually edited as they presented two additional nucleotides generating a frameshift in the predicted coding region and numerous stop codons. For DB2 and DB4 sequences, one thymine was removed from position 345-346 and another for position 426-427. For DB3 sequence, the same nucleotides were removed from position 315-316 and position 396-397. As control, consensus sequences were compared against the Identification System of BOLD (www.boldsystems.org) and the BLAST web application of GenBank (https://blast.ncbi.nlm.nih.gov/Blast.cgi).

\section{Phylogenetic analyses}

For phylogenetic analyses, a few additional Spirostreptidae Brandt, 1833 sequences from GenBank and BOLD (see Appendix 2) were selected based on BOLD and BLAST 's comparative results. Although this set of taxa does not represent an exhaustive list, we estimate it sufficient to evaluate the relationships of the new species. In addition, some representatives of the family Harpagophoridae Attems, 1909 (Thyropygus spp.) were chosen as outgroup. All sequences of each marker were aligned with MAFFT ver. 7 implemented online (Katoh \& Standley 2013) with default settings. Both COI and 16S alignments were cured (by removing ambiguous sites and trimming datasets) using the least stringent settings in Gblocks 0.91b online (Castresana 2000; Talavera \& Castresana 2007; Gblocks Server available online at http://molevol.cmima.csic.es/castresana/Gblocks_server.html). Finally, a combined COI-16S alignment was created with Mesquite ver. 3.5 (Maddison \& Maddison 2018) by concatenating the Gblocks curated alignments of the two markers. Best partition scheme and best-fit substitution models (see Appendix 3) were estimated using PartitionFinder 2 (Lanfear et al. 2016) on the basis of one partition for 16S and three for COI (protein coding gene partitioned into single codon positions). 
Phylogenetic reconstructions were evaluated using statistical approaches including maximum likelihood (ML) using GARLI ver. 2.01 (Zwickl 2006) and Bayesian inferences, the latter utilizing MrBayes ver. 3.2.7a (Ronquist et al. 2012) (MB) and Phylobayes MPI ver. 1.5a (Lartillot et al. 2009) (PB), all performed on the CIPRES Science Gateway ver. 3.3 (Miller et al. 2010). For the MB analysis, two parallel runs (with four chains each) were executed for ten million generations. Parameters were estimated independently for each partition using the following command: unlink statefreq $=($ all $)$ revmat $=($ all $)$ shape $=($ all $)$ pinvar $=($ all $)$ tratio $=($ all $)$. Trees were sampled every $1000^{\text {th }}$ generations and were used to reconstruct a 50\% majority rule consensus tree after having discarded the first $25 \%$ as 'burn-in'. Analysis in PB was conducted under the $\mathrm{CAT}+\mathrm{GTR}+\mathrm{Gamma}$ substitution model (with maxdiff" value set to 0.1 Minimum Effective Size to 300 and excluding the 1000 first of cycles from convergence checks). Analyses using the ML method were conducted in GARLI with 1000 bootstrap replicates. Values were then summarized on the best ML tree using SumTree ver. 4.0.0 (Sukumaran \& Holder 2015) (run in DendroPy ver. 4.0.0, Sukumaran \& Holder 2010).

In addition, estimations of the average evolutionary divergences for each marker (based on a MAFFT alignments of the sequenced specimens only) were calculated in MEGA-X (Kumar et al. 2018; Stecher et al. 2020) as the number of base differences per site (P-distance) from between sequences and species group with the option 'Pairwise deletion'.

\section{Results}

\section{Phylogeny}

Amplification and sequencing provided a fragment length of about $730-900 \mathrm{bp}$ for COI (partial sequence of $200 \mathrm{bp}$ only for two samples, DS1 and DS2, could be retrieved) and about $500 \mathrm{bp}$ for 16S. The combined COI-16S final dataset comprised 1051 sites (561 bp for COI and $490 \mathrm{bp}$ for 16S).

All phylogenetic analyses provided congruent results with identical tree topologies. The Figure 1 presents the tree resulting from the MB analysis on which the support values of PB and ML are also summarized. The genus Sechelleptus represented here by S. variabilis, S. arborivagus sp. nov. and an undetermined species (i.e., DU1, a sub-adult female collected at Mont Combani on Mayotte) is strongly recovered as monophyletic in all analyses and appears sister to an unidentified dipoplod from Madagascar (for which the COI sequence was retrieved from BOLD, see Appendix 2). Both S. variabilis and S. arborivagus sp. nov. are recovered with high support, but their relationship with DU1 is not clearly resolved.

The relationships among the outgroups were not the primary focus of the present study, but are consistent with previous studies (Mwabvu et al. 2013, 2015; Tinago et al. 2017) that showed paraphyletic groups suggesting the presence of cryptic species (i.e., Bicoxidens spp.) and possible identification errors in the GenBank database.

\section{Genetic distances}

The MAFFT alignment of the sequenced specimens used for calculations in MEGA-X provided datasets of 1007 positions for COI and 502 positions for 16S. Little genetic variation is observed between the sequenced individuals of Sechelleptus arborivagus sp. nov. compared to S. variabilis (see Table 2). For $S$. arborivagus sp. nov., the within mean group distance calculated in MEGA-X is very low: $0.1 \%$ for COI and $0.2 \%$ for $16 \mathrm{~S}$. These values are much higher within S. variabilis, being $4.9 \%$ and $1.5 \%$ respectively.

The genetic distance between S. arborivagus sp. nov. (DB) and S. variabilis (DS) is about $22.6 \%$ for COI and $6.9 \%$ for $16 \mathrm{~S}$ (Table 3). The undetermined Sechelleptus (DU1) from Mont Combani also showed the same range of genetic differences between DB and DS: respectively $17.5 \%$ and $14 \%$ for COI and $7 \%$ and 
Table 2. Estimates of Evolutionary Divergence between Sequences. The number of base differences per site between sequences are shown. DB1-DB4 = Sechelleptus arborivagus sp. nov.; DS1-DS3 = Sechelleptus variabilis VandenSpiegel \& Golovatch, 2007; DU1 = Sechelleptus sp. Molecular analyses were conducted in MEGA X (Kumar et al. 2018; Stecher et al. 2020).

\begin{tabular}{|c|c|c|c|c|c|c|c|c|}
\hline COI & DB1 & DB2 & DB3 & DB4 & DS1 & DS2 & DS3 & DU1 \\
\hline DB1 & & $0.40 \%$ & $0.00 \%$ & $0.00 \%$ & $7.01 \%$ & $7.20 \%$ & $6.41 \%$ & $7.00 \%$ \\
\hline DB2 & - & & $0.40 \%$ & $0.40 \%$ & $7.21 \%$ & $7.40 \%$ & $6.61 \%$ & $7.00 \%$ \\
\hline DB3 & - & $0.14 \%$ & & $0.00 \%$ & $7.01 \%$ & $7.20 \%$ & $6.41 \%$ & $7.00 \%$ \\
\hline DB4 & - & $0.00 \%$ & $0.14 \%$ & & $7.01 \%$ & $7.20 \%$ & $6.41 \%$ & $7.00 \%$ \\
\hline DS1 & - & $25.00 \%$ & $22.03 \%$ & $25.00 \%$ & & $1.80 \%$ & $1.00 \%$ & $8.62 \%$ \\
\hline DS2 & - & $25.52 \%$ & $25.22 \%$ & $25.52 \%$ & $6.34 \%$ & & $1.60 \%$ & $8.00 \%$ \\
\hline DS3 & - & $18.27 \%$ & $18.07 \%$ & $18.33 \%$ & $3.90 \%$ & $4.46 \%$ & & $8.42 \%$ \\
\hline DU1 & - & $17.51 \%$ & $17.35 \%$ & $17.58 \%$ & $14.90 \%$ & $15.61 \%$ & $11.60 \%$ & \\
\hline
\end{tabular}

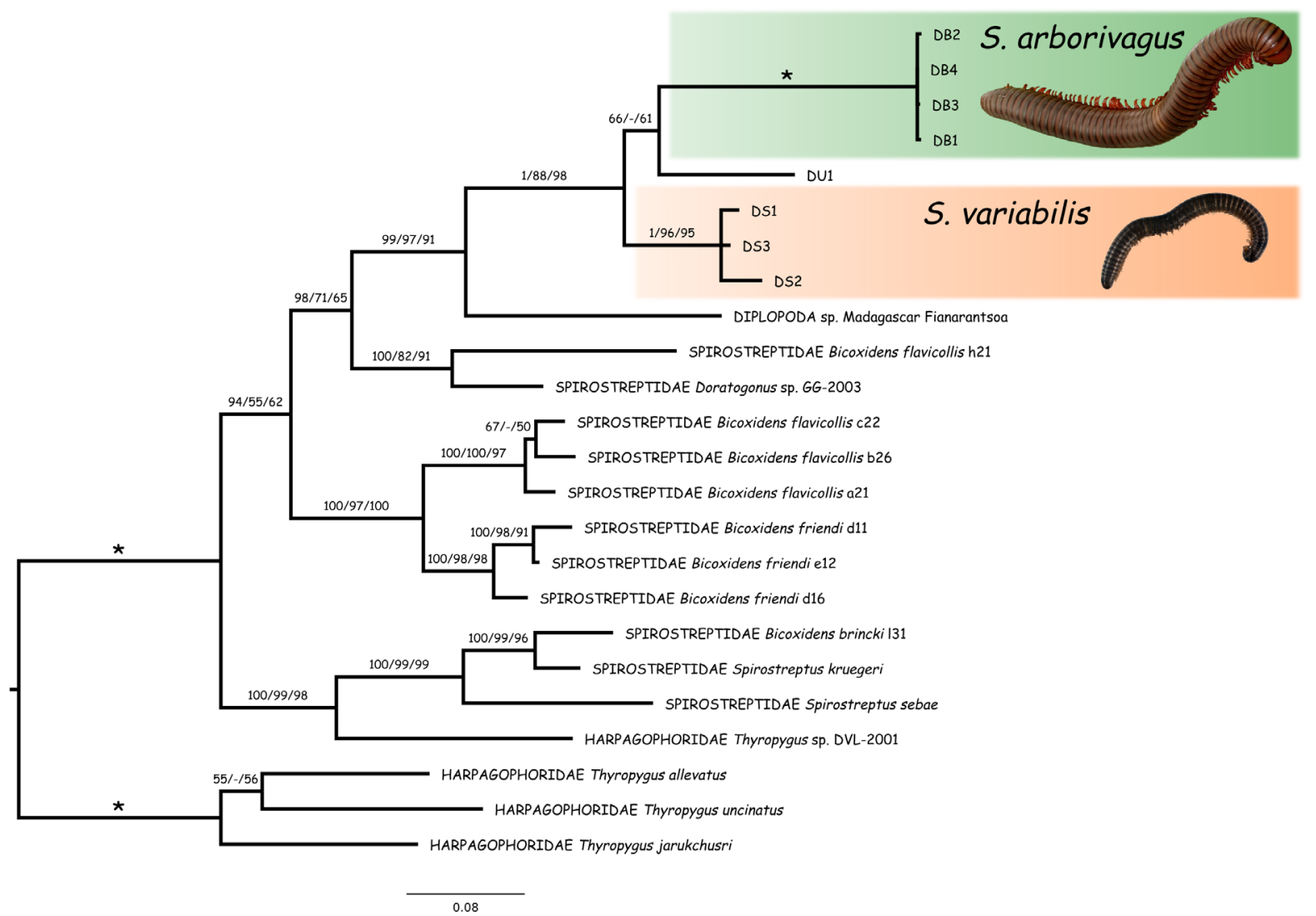

Fig. 1. Bayesian Inference tree resulting from the MB analysis based on the COI-16S dataset, showing relationships between Sechelleptus arborivagus sp. nov. and other relatives of the family Spirostreptidae Brandt, 1833 and outgroups Harpagophoridae Attems, 1909. The tree is congruent in its topology with the PB and ML analyses of the same dataset. Nodal support values (MB and PB posterior probabilities and ML Bootstrap) are indicated as following: MB/PB/ML. Stars designate absolute supports (i.e., 100 in all three analyses), and hyphens indicate collapsed nodes in the PB tree. 
Table 3. Estimates of Evolutionary Divergence over Sequence Pairs between Groups. The number of base differences per site averaging over all sequence pairs between groups are shown. $\mathrm{DB}=$ Sechelleptus arborivagus sp. nov. (DB2-DB4 in COI dataset, DB1-DB4 in 16S dataset); DS = Sechelleptus variabilis VandenSpiegel \& Golovatch, 2007 (DS1-DS3); DU = Sechelleptus sp. (DU1). Molecular analyses were conducted in MEGA X (Kumar et al. 2018; Stecher et al. 2020).

\begin{tabular}{cccccc}
\hline COI & & 16S & \multicolumn{1}{c}{ DB } & DS & DU \\
\hline & DB & & $6.93 \%$ & $7.00 \%$ \\
& & & & $8.34 \%$ \\
& DS & $22.55 \%$ & & \\
& DU & $17.48 \%$ & $14.04 \%$ & \\
\hline
\end{tabular}

$8.3 \%$ for $16 \mathrm{~S}$ (Table 3). The overall mean distances within Sechelleptus (calculated as the estimates of average evolutionary divergence over all sequence pairs) is $14.9 \%$ for COI and $5.1 \%$ for $16 \mathrm{~S}$ (Tables $2-3$ ).

\section{Systematics}

Class Diplopoda De Blainville in Gervais, 1844

Order Spirostreptida Brandt, 1833

Suborder Spirostreptidea Brandt, 1833

Family Spirostreptidae Brandt, 1833

Genus Sechelleptus Mauriès, 1980

Sechelleptus Mauriès, 1980: 147.

Rubanostreptus Krabbe, 1982: 183, synonymized by Golovatch \& Korsós (1992).

Sechelleptus - Golovatch \& Korsós 1992: 24.

\section{Type species}

Iulus seychellarum Desjardins, 1835

Diagnosis (adapted from Mauriès 1980 and Golovatch \& Korsós 1992)

A genus of moderate to large spirostreptid millipedes (up to $120 \mathrm{~mm}$ long) characterized by the rather simple gonocoxite and the long, slender, ribbon-shaped gonotelopodite with a spine arising well distad of the knee and a small free solenomerite arising just near the apex.

\section{Distribution}

Tanzania, Zanzibar, Comoros archipelago, Seychelles, Madagascar, Mauritius.

Species included (adapted from Millibase: Sierwald \& Spelda 2021)

Sechelleptus aberrans (Brölemann, 1923); http://www.millibase.org/aphia.php?p=taxdetails\&id=1044974

S. anulatus (Attems, 1914); http://www.millibase.org/aphia.php? $\mathrm{p}=$ taxdetails\&id=999985

S. $\arg u$ (Attems, 1896); http://www.millibase.org/aphia.php? $\mathrm{p}=$ taxdetails\&id=998239

S. betaminena (De Saussure \& Zehntner, 1902); http://www.millibase.org/aphia.php?p=taxdetails\&id=1044975

S. confusus (Attems, 1950); http://www.millibase.org/aphia.php? $\mathrm{p}=$ taxdetails\&id=1044977

S. coriaceus (De Saussure \& Zehntner, 1901); http://www.millibase.org/aphia.php?p=taxdetails\&id=998243

S. dauphini (De Saussure \& Zehntner, 1902); http://www.millibase.org/aphia.php?p=taxdetails\&id=998244 
S. fulgens (De Saussure \& Zehntner, 1901); http://www.millibase.org/aphia.php? $\mathrm{p}=$ taxdetails\&id=998237

S. gonospinosus (Atems, 1910); http://www.millibase.org/aphia.php?p=taxdetails\&id=1044978

S. kalobaptus (Attems, 1914); http://www.millibase.org/aphia.php? $\mathrm{p}=$ taxdetails\&id=1044979

S. krabbae Jeekel, 1999; http://www.millibase.org/aphia.php?p=taxdetails\&id=940073

S. lambertoni (Brölemann, 1923); http://www.millibase.org/aphia.php?p=taxdetails\&id=1155959

S. lobifer (Attems, 1951); http://www.millibase.org/aphia.php?p=taxdetails\&id=1044980

S. macilentus (De Saussure \& Zehntner, 1897); http://www.millibase.org/aphia.php?p=taxdetails\&id=998247

S. metazonalis (De Saussure \& Zehntner, 1901); http://www.millibase.org/aphia.php?p=taxdetails\&id=998238

S. moramangae (De Saussure \& Zehntner, 1897); http://www.millibase.org/aphia.php?p=taxdetails\&id=998249

S. multiporus (Attems, 1951); http://www.millibase.org/aphia.php? $\mathrm{p}=$ taxdetails\&id=1246528

S. nigritus (De Saussure \& Zehntner, 1897); http://www.millibase.org/aphia.php? $\mathrm{p}=$ taxdetails\&id=998250

S. obscuratus (Attems, 1914); http://www.millibase.org/aphia.php?p=taxdetails\&id=1248577

S. obscurus (Attems, 1951); http://www.millibase.org/aphia.php? $\mathrm{p}=$ taxdetails\&id=1248590

S. piesthopygus (Attems, 1914); http://www.millibase.org/aphia.php?p=taxdetails\&id=999987

S. praepolitus (Attems, 1910); http://www.millibase.org/aphia.php?p=taxdetails\&id=1248594

S. procerus (Attems, 1951); http://www.millibase.org/aphia.php? $\mathrm{p}=$ taxdetails\&id=1249715

S. punctatulus (Attems, 1910); http://www.millibase.org/aphia.php? $\mathrm{p}=$ taxdetails\&id=1249718

S. pyrhozonus (Gerstäcker, 1873); http://www.millibase.org/aphia.php?p=taxdetails\&id=998242

S. scabricollis (De Saussure \& Zehntner, 1897); http://www.millibase.org/aphia.php?p=taxdetails\&id=998252

S. seychellarum (Desjardins, 1835); http://www.millibase.org/aphia.php? $\mathrm{p}=$ taxdetails\&id=947475

S. speculorbis (Attems, 1910); http://www.millibase.org/aphia.php?p=taxdetails\&id=1249894

S. sulcicollis (De Saussure \& Zehntner, 1897); http://www.millibase.org/aphia.php?p=taxdetails\&id=999880

S. unilineatus Golovatch \& Korsós, 1992; http://www.millibase.org/aphia.php?p=taxdetails\&id=940074

S. variabilis VandenSpiegel \& Golovatch, 2007; http://www.millibase.org/aphia.php?p=taxdetails\&id=1024527

S. arborivagus sp. nov.

\section{Key to species of Sechelleptus}

Waiting a complete revision work of the genus, only the following additional lines to the key of Jeekel (1999) is given here:

22. Metaplica (posterior blade) with a small latero-distal uncus. Number of body rings 49-52, width $7.0-8.0 \mathrm{~mm}$ S. sulcicollis (De Saussure \& Zehntner, 1897)

- Metaplica without latero-distal uncus. Number of body rings usually higher $.22 \mathrm{~A}$

22A. Metaplica simply widened. Number of body rings 59, width $12.0 \mathrm{~mm}$

S. macilentus (De Saussure \& Zehntner, 1897)

- $\quad$ Metaplica widened and a little higher than proplica (anterior blade) 22B

22B. Proplica with a lateral finger-shaped lobe. Number of body rings 50-60, width 3.0-5.0 mm

S. variabilis VandenSpiegel \& Golovatch, 2007

- Proplica ending apically in a more or less spiniform mesapical projection. Number of body rings 57-62, width 7.0-9.0 $\mathrm{mm}$

S. arborivagus sp. nov.

Sechelleptus variabilis VandenSpiegel \& Golovatch, 2007

Fig. 2

\section{Material examined}

\section{Holotype}

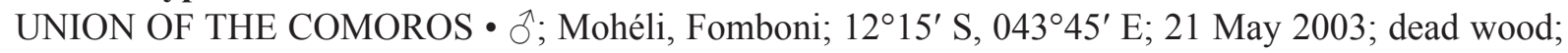
R. Jocqué and D. VandenSpiegel leg.; BE_RMCA_MYR.Dip.21733. 

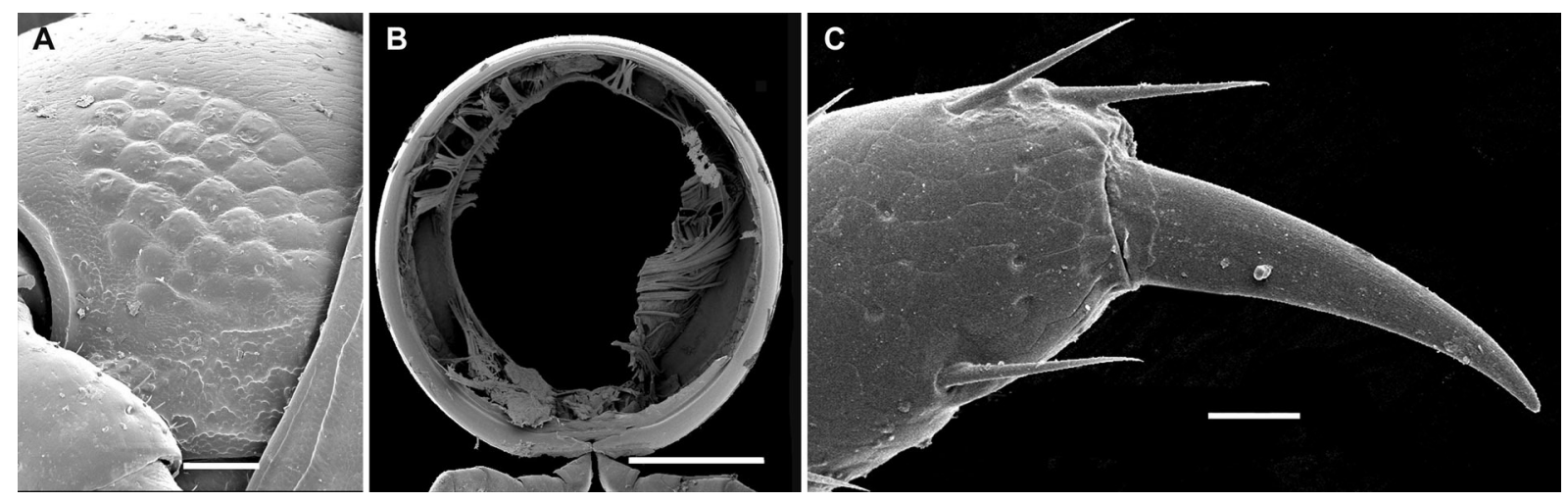

Fig. 2. Sechelleptus variabilis VandenSpiegel \& Golovatch, 2007 (BE_RMCA_MYR.Dip.22883). SEM views. A. Ommatidia, lateral view. B. Transversal section of midbody, frontal view. C. Tarsal claw, lateral view. Scale bars: $A=100 \mu \mathrm{m} ; \mathrm{B}=1 \mathrm{~mm} ; \mathrm{C}=20 \mu \mathrm{m}$.

\section{New material}

FRANCE - Department of Mayotte (Comoros archipelago) 1 ; ; Mereni, back of mangrove; 19 Nov. 2019; hand collecting; D. VandenSpiegel and A. Mathys leg.; BE_RMCA_MYR.Dip.22878 • 1 万, 1 क; same collection data as for preceding; 21 Nov. 2019; BE_RMCA_MYR.Dip.22879 • 1 §ै; same collection data as for preceding; BE_RMCA_MYR.Dip.22983 - 1 ō, 1 9 ; Mont Benara; $12^{\circ} 52^{\prime} \mathrm{S}$, $045^{\circ} 09^{\prime}$ E; 21 Nov. 2019; hand collecting \& sieving, litter; D. VandenSpiegel and A. Mathys leg.; BE_ RMCA_MYR.Dip.22883 - 1 त亍; Mont Combani, $500 \mathrm{~m}$ before Lodge; $12^{\circ} 47^{\prime} \mathrm{S}, 045^{\circ} 09^{\prime} \mathrm{E}$; 15 Nov. 2019; sieving; litter; D. VandenSpiegel and A. Mathys leg.; BE_RMCA_MYR.Dip.22930.

\section{Remarks}

In the original description of the species, the length unit given for the specimens' sizes is wrong and should have been $\mathrm{cm}$ instead of $\mathrm{mm}$. Correct measurements are: length $\widehat{\partial} \delta^{\lambda}: 3.4-8.0 \mathrm{~cm}$; 우 $O$ : 5.0 $7.0 \mathrm{~cm}$; midbody width $0.34-0.5 \mathrm{~cm}$ and $0.3-0.5 \mathrm{~cm}$, respectively.

Taking this modification into account, the recently collected specimens agree with the description (VandenSpiegel \& Golovatch 2007).

Sechelleptus arborivagus sp. nov.

urn:1sid:zoobank.org:act:0F7B3368-17F8-4CAD-8B11-C34B564FE8DE

Figs 3-8

\section{Diagnosis}

A medium-sized arboreal millipede with relatively long legs, particularly similar to $S$. variabilis by sharing the structure of the male first leg and rather simple gonopods with the metaplica widened and a little higher than proplica, the latter without lateral cone. The two species differ by the gonotelopodite being apically divided in two branches in S. arborivagus sp. nov. and simple in S. variabilis.

\section{Etymology}

Referring to the ecology of the species, which has always been observed climbing trees. 


\section{Material examined}

\section{Holotype}

FRANCE - Department of Mayotte (Comoros archipelago) • đ̄; Mt. Tchaourembo; 12 $52^{\prime} 14^{\prime \prime} \mathrm{S}$, 0450' $44^{\prime \prime}$ E; 540-550 m a.s.1.; 25 Nov. 2019; D. VandenSpiegel and A. Mathys leg.; on tree; by hand; GenBank accession numbers: MW168813 (COI), MW148622 (16S rRNA); BE_RMCA_MYR. Dip.22874.

\section{Paratypes}

FRANCE - Department of Mayotte (Comoros archipelago) • 1 O, 1 ; ; same collection data as for holotype; GenBank accession numbers: MW168814 (COI), MW148623 (16S rRNA); BE_RMCA MYR.Dip.22875 • 9 q ; same collection data as for holotype; GenBank accession numbers: MW168815 (COI), MW148624 (16S rRNA); BE_RMCA_MYR.Dip.22876.

\section{Additional material}

FRANCE - Department of Mayotte (Comoros archipelago) • 1 웅 Mt. Benara; $12^{\circ} 52^{\prime} \mathrm{S}, 045^{\circ} 11^{\prime} \mathrm{E}$; 23 Jan. 1999; R. Jocqué and G. De Smet leg.; forest; by hand; GenBank accession numbers: MW148621 (16S rRNA); BE_RMCA_MYR.Dip.17917.

\section{Description}

\section{Holotype}

With 57 body rings (plus telson, no apodous rings); ca $100 \mathrm{~mm}$ long, $7 \mathrm{~mm}$ wide.

Live COLORATION (Fig. 3). Head, collum, antennae, telson, anal valves and legs uniformly light brownish to dark brownish. Metazonae light brown to red-brown. Posterior margin of metazonites dark brown.

HEAD. Smooth. Each eye patch with circa 60 ommatidia arranged in seven horizontal rows (Fig. 4A), Labrum with three smoothly rounded teeth and a single row of 21 short labral setae (Fig. 4G). Clypeus with four supra-labral setae, two on each side (Fig. 4G). Antennae moderately long (Fig. 3), protruding back to ring 2. Relative length of antennomeres: $1>2>3=4=5>6$. Terminal antennomere (disc) with four large sensory cones located together inside a membranous area. Each of antennomeres 5 and 6 apicolaterally with a field of narrow and long sensilla basiconica (Fig. 4B). Gnathochilarium, usual for spirostreptideans (Fig. 4D). Prementum (pm) smooth and straight, not depressed. Mentum (me) smooth.
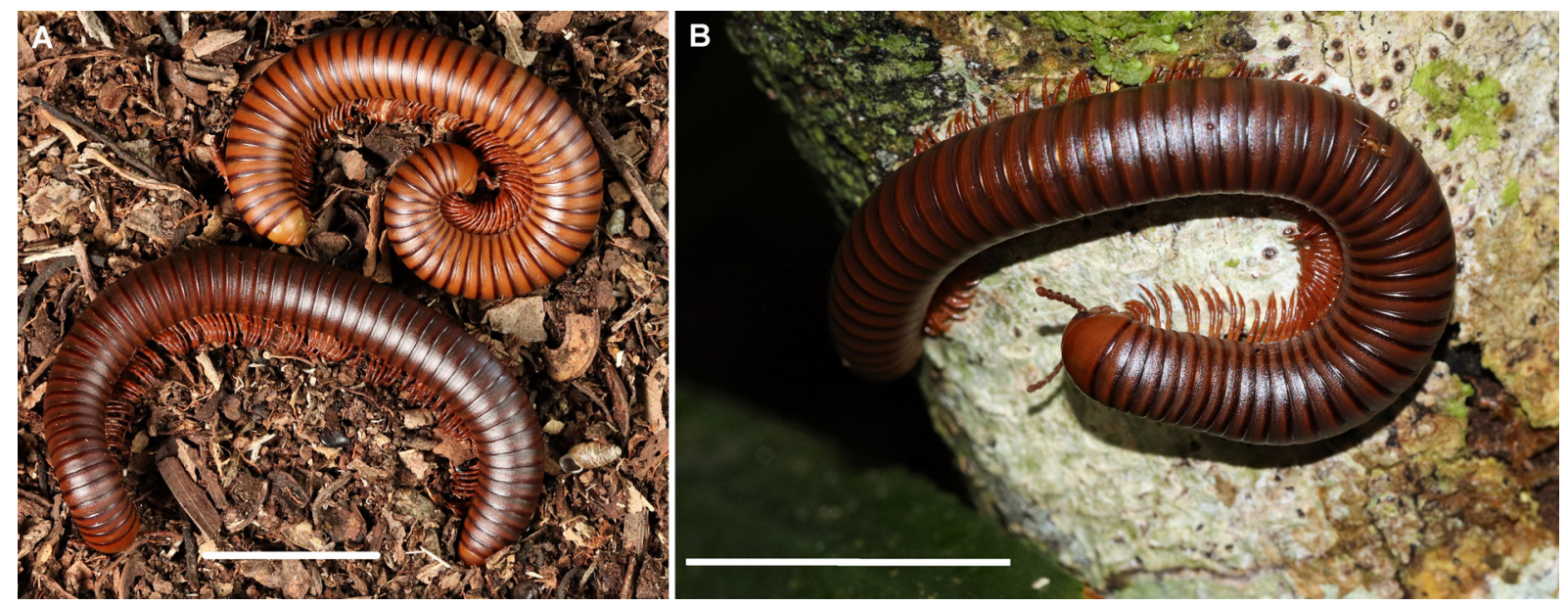

Fig. 3. Sechelleptus arborivagus sp. nov., in vivo habitus. A. Two females showing different color. B. Female on tree. Scale bars $=3 \mathrm{~cm}$. 

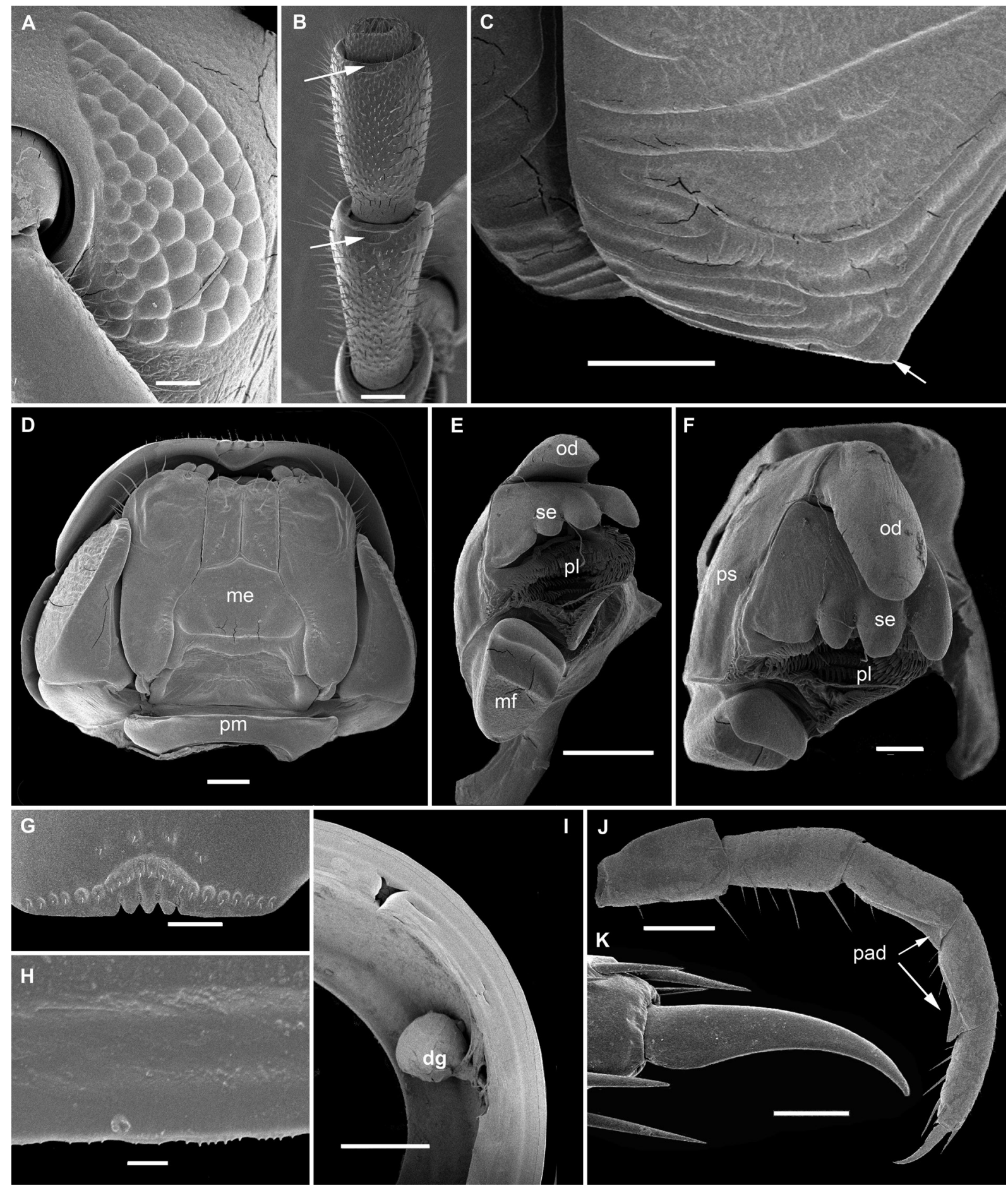

Fig. 4. Sechelleptus arborivagus sp. nov., paratype, ô (BE_RMCA_MYR.Dip.22875). SEM views. A. Ommatia, frontal view. B. Antennae, ventral view, arrows pointing to sensilla basiconica. C. Lateral view of collum, arrows pointing to the anteroventral angle $80-90^{\circ}$. D. Head, ventral view. E. Mandible, ventral view. F. Mandible, frontal view (F). G. Clypeus, frontal view. H. Limbus. I. Defensive gland. J. Walking leg, lateral view. K. Tarsal claw, lateral view. Abbreviations: $\mathrm{dg}=$ defensive gland; $\mathrm{me}=$ mentum; od = odontomere; $\mathrm{pl}=$ pectinate lamellae; $\mathrm{pm}=$ prementum; $\mathrm{pad}=$ tibial $\mathrm{pad} ; \mathrm{ps}=$ psectomere; $\mathrm{se}=$ sectile edge. Scale bars: A-B, F $=200 \mu \mathrm{m} ; \mathrm{C}-\mathrm{E}, \mathrm{G}, \mathrm{J}=500 \mu \mathrm{m} ; \mathrm{H}=5 \mu \mathrm{m} ; \mathrm{I}=1 \mathrm{~mm} ; \mathrm{K}=100 \mu \mathrm{m}$. 


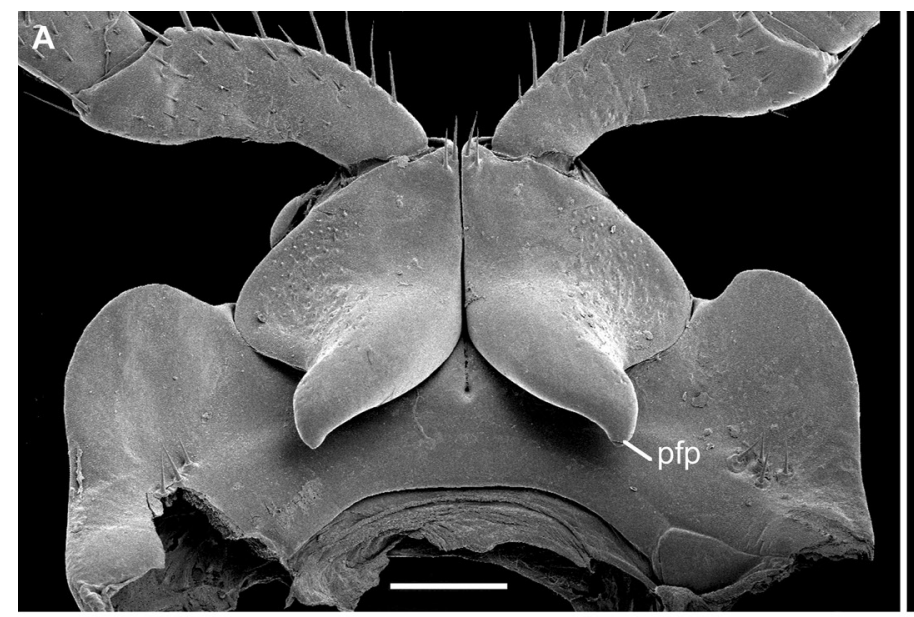

B
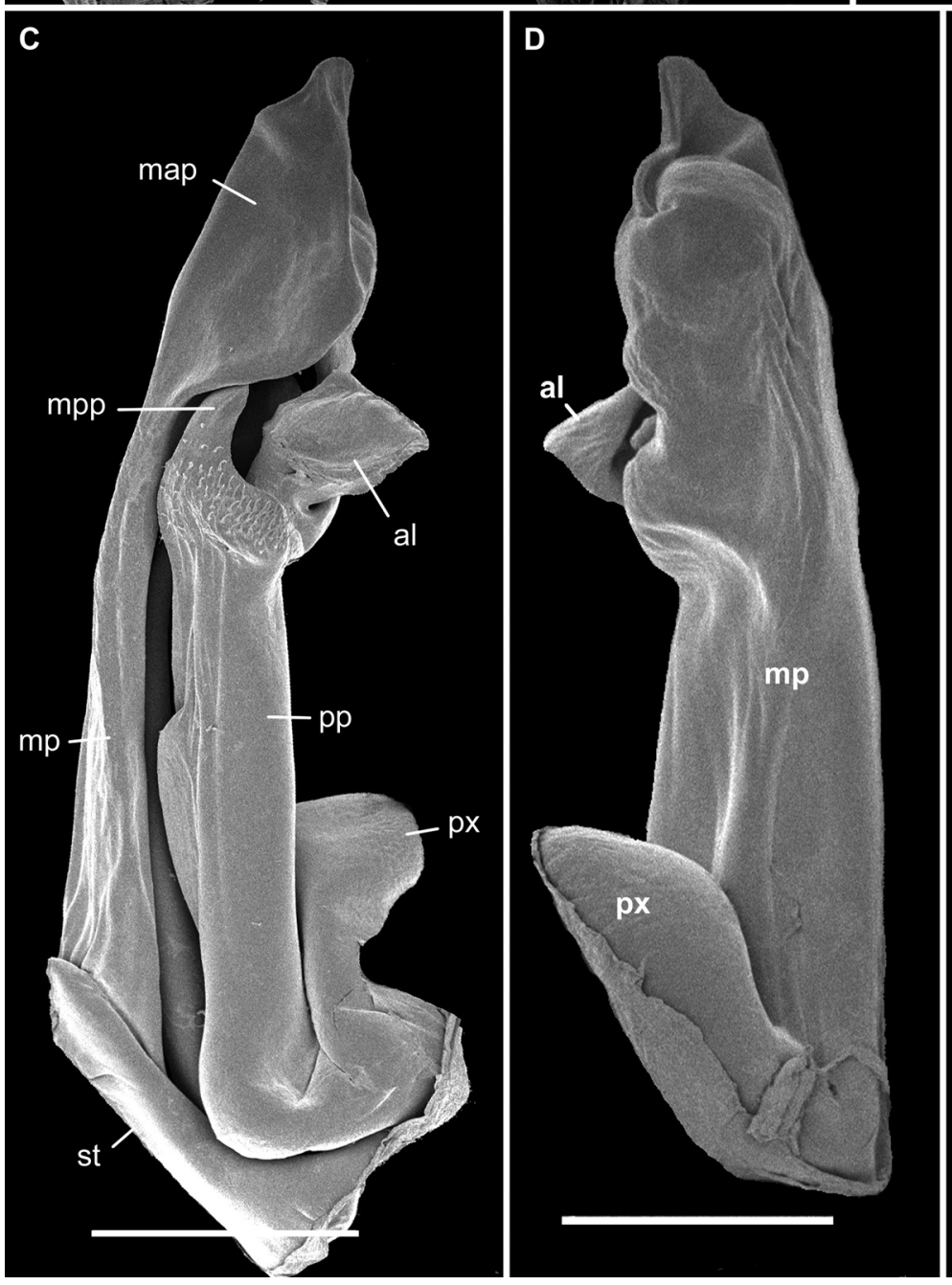

E
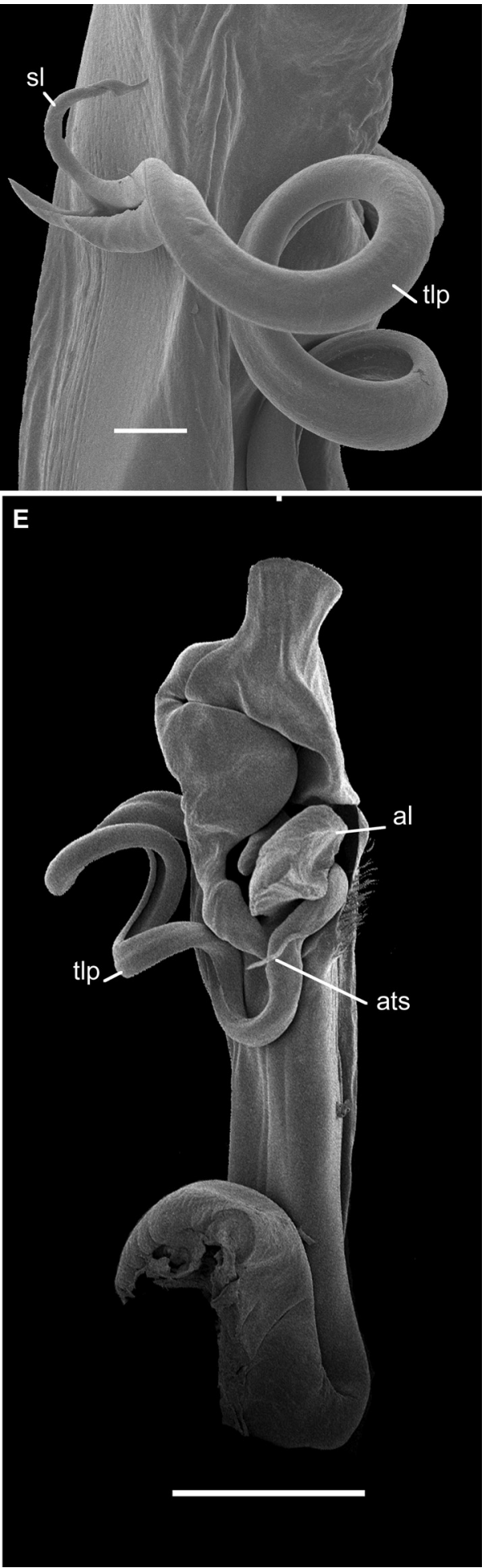

Fig. 5. Sechelleptus arborivagus sp. nov., paratype, đ (BE_RMCA_MYR.Dip.22875). SEM views. A. First pair of legs, frontal view. B. Apical part of gonopod telopodite. C. Gonocoxite, oral view. D. Gonocoxite, caudal view. E. Gonopod, lateral view. Abbreviations: al = apicolateral lamellose lobe; ats $=$ antetorsal process; $\mathrm{mp}=$ metaplica $; \mathrm{mpp}=$ mesaplical projection; $\mathrm{pfp}=$ prefemoral process; $\mathrm{pp}=$ proplica; $\mathrm{px}=$ paracoxite; $\mathrm{sl}=$ solenomere; $\mathrm{st}=$ sternite; tlp $=$ telopodite. Scale bars: $\mathrm{A}=500 \mu \mathrm{m} ; \mathrm{B}=$ $100 \mu \mathrm{m} ; \mathrm{C}-\mathrm{E}=1 \mathrm{~mm}$. 


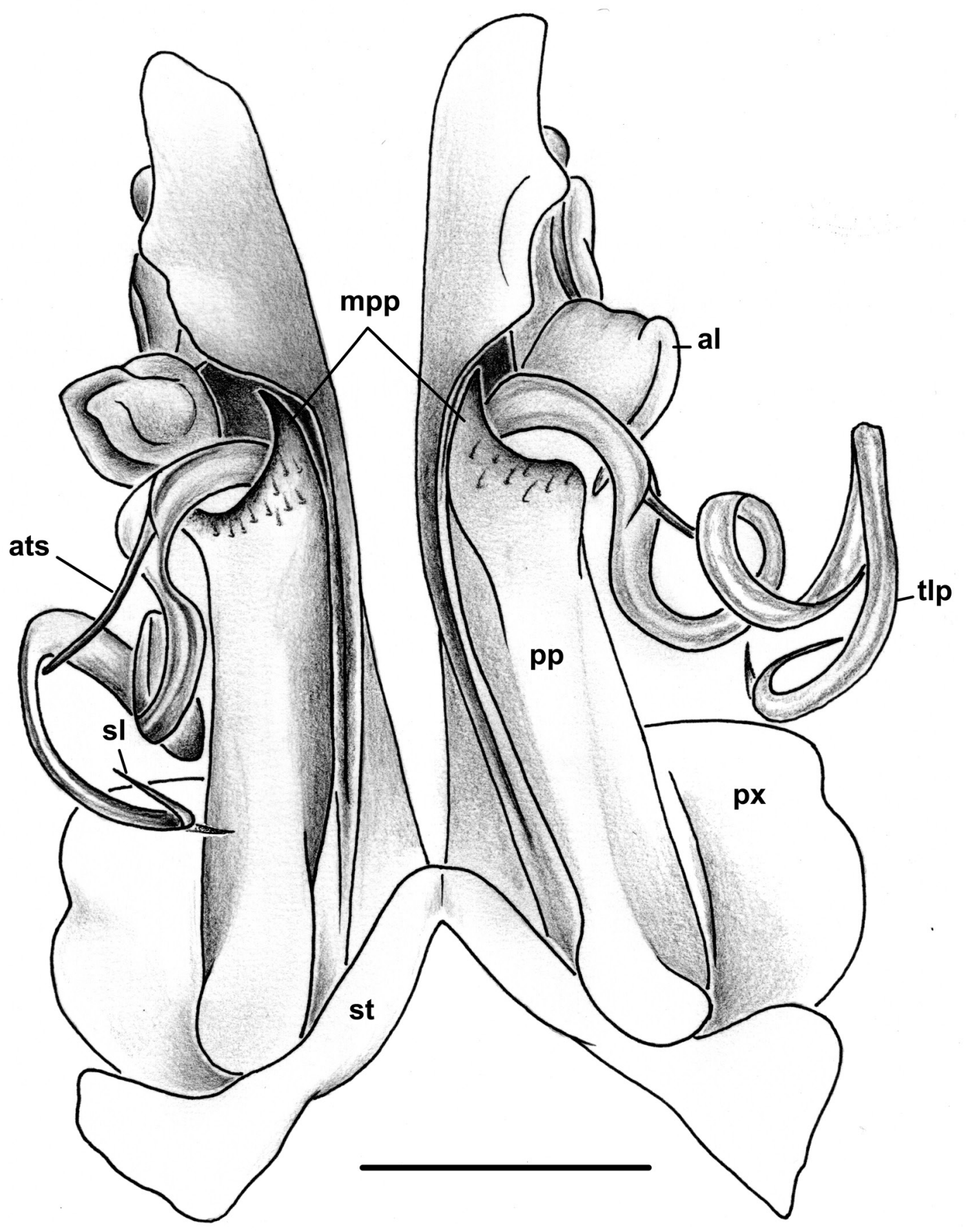

Fig. 6. Sechelleptus arborivagus sp. nov., paratype, ô (BE_RMCA_MYR.Dip.22875). Drawing of the gonopods, oral view. Abbreviations: $\mathrm{al}=$ apicolateral lamellose lobe; ats $=$ antetorsal process; $\mathrm{mpp}=$ mesaplical projection; $\mathrm{pp}=$ proplica; $\mathrm{px}=$ paracoxite; $\mathrm{sl}=$ solenomere; $\mathrm{st}=$ sternite; $\mathrm{tl}$ = telopodite. Scale bar $=1 \mathrm{~mm}$. 
Lamellae linguales each with two strong apical setae, one equally strong seta behind these, plus, basally, an oblique line of four setae. Stipites with a basal longitudinal field of setae, lateral margin in distal half with a row of setae; one isolated, subapical, stout seta or sensillum; cardo small, kidney-shaped. Mandibles (Fig. 4E, F) with stipes devoid of differentiation. Odontomere (od) long, moveable. Sectile edge (se) of psectromere (ps) with four lobes; eight pectinate lamellae (pl). One wide molar furrow (mf).

Collum. Smooth, ventrally with six longitudinal furrows, anteroventral angle $80-90^{\circ}$.

Body RINGS. Prozonae smooth. Metazonae with longitudinal striae ventrally from ca $2 / 3$ ring length below ozopore. Ozopores located on metazonae, starting with ring 6, located close to, but not touching the suture between pro- and metazonae. Limbus simple (Fig. 4H). Defensive glands well-developed (Fig. 4I).

TELson. Preanal ring with a shallow submarginal depression. Anal valves smooth, without submarginal depression. Hypoproct, small, widely triangular.

LEGS. Length $0.45-0.5 \times$ body diameter, postfemoral and tibial pads (Fig. $4 \mathrm{~J}$ ) from third male leg-pair until beyond midbody, pads decreasing in size posteriorly; claw large, curved (Fig. 4K). First pair of male legs with a well-developed prefemoral process ending in an inward curved tip (Fig. 5A). Coxosternum with a laterobasal field of four strong setae on anterior side.

Gonopods (Figs 5B-E, 6). Sternum (st) triangular, not reaching as far distad as paracoxite (px). Metaplica $(\mathrm{mp})$ higher than proplica, rounded apically (Fig. 5C; mp). Proplica with straight sides, in apical part with scattered short setae, ending apically in a more or less spiniform mesapical projection (Fig. 5C; mpp) and a well-developed, apicolateral, lamellose lobe (Fig. 6C; al); telopodite (Fig. 5B, E; tlp) long and slender, without a distinct demarcation between femoral and postfemoral parts, femorite with a small and pointed antetorsal process (Fig. 5E; ats), postfemorite spiralled, ribbon-shaped, broad and long, with a divided tip, the longer branch carrying the terminal opening of the solenomere (Fig. 5B; sl).

\section{Paratypes}

Male similar to holotype.
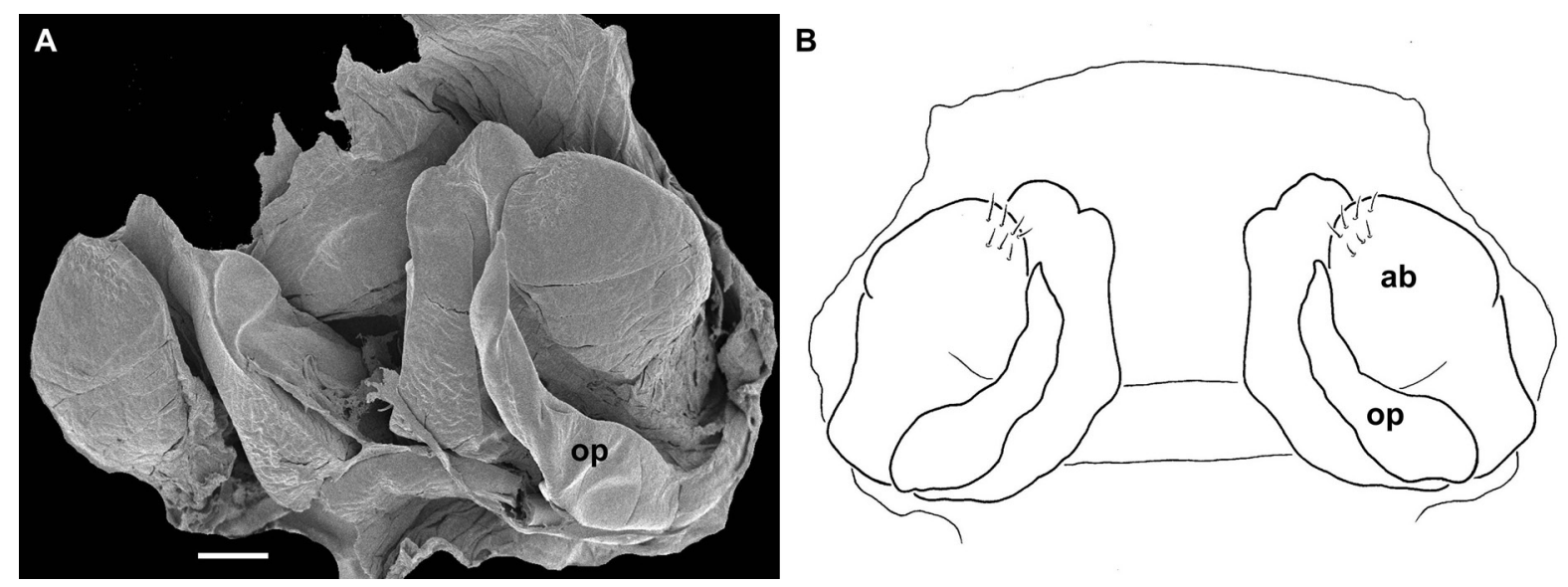

Fig. 7. Sechelleptus arborivagus sp. nov., paratype, $q$ (BE_RMCA_MYR.Dip.22876). Vulva. A. SEM of the vulva removed from the body, caudal view, slightly lateral. B. Drawing of the vulva, caudal view. Abbreviations: $\mathrm{ab}=$ aboral valve; $\mathrm{op}=$ opercula. Scale $\mathrm{bar}=100 \mu \mathrm{m}$. 
Female coloration as in male, but generally larger in size than male (up to $120 \mathrm{~mm}$ long $9 \mathrm{~mm}$ wide (58-61 body rings plus telson, no apodous rings). Vulvae located in membranous pouches attached to coxae 2 and 3 and to the inner lateral margin of ring 1, simple, consisting of two simple, subequallysized, moderately sclerotized valves, the aboral valve with an apical cluster of setae; ridge between valves covered with a lateral longitudinal operculum (Fig. 7).

\title{
Distribution
}

The species seems endemic to Mayotte (Fig. 8).

\begin{abstract}
Affinities
On the basis of the gonopod structure having the telopodite with a spine arising well distad of the knee, a ribbon-shaped distal part, and a small free solenomerite arising just near the apex, the new species is manifestly a new member of the large genus Sechelleptus. Following the key published by Jeekel in 1999, arborivagus keys out close to sulcicollis and macilentus. Indeed the three species have a rather simple gonocoxite with a distally widened metaplica without a strong lateral cone but the new species do not show the small lateral uncus present on the metaplica of sulcicolis and possess a more or less spiniform mesapical projection on the proplica which is not present in sulcicolis neither in macilentus. By the overall shape of the male first leg and gonocoxite, the new species seems to be especially close to $S$. variabilis, also from the Comoros, but it differs strikingly by the structure of the gonotelopodite (in $S$. variabilis the gonotelopodite has a simple and pointed tip carrying the terminal opening of the seminal groove whereas in the new species the gonotelopodite has a divided tip, the longer branch carrying the terminal opening of the seminal groove) as well as by the larger body size and the longer and curved claws (Fig. 4K vs Fig. 2C). Other important differences concern the defensives glands, large in S. arborivagus sp. nov. (Fig. 4I) (vs inconspicuous in S. variabilis (Fig. 2A)), and the size of eyes: in the new specie the eyes are larger and include $60 \pm 5$ ommatidia $(n=10)$ arranged in 12 rows; whereas in $S$. variabilis the eyes, smaller, include $34 \pm 3(\mathrm{n}=10)$ ommatidia arranged in 9 rows.
\end{abstract}

\section{Natural history}

Most of the specimens belonging to the new species were collected on Mt Tchaourembo (see Fig. 8) in a forest fragment at 500-550 m a.s.1. All specimens were seen in trees and never in pairs, the males being rare (sex ratio $>1 / 6$ ). The species possesses enlarged ommatidia, relatively long legs with strongly curved tarsal claws, as well as a tendency for specimens to secrete extremely copiously from their defensive glands when irritated. Such modifications are considered by several authors as an adaptation to tree climbing and to arboreal life (Enghoff \& Enghoff 1976; Hoffman \& Howell 1983; VandenSpiegel 2001).

\section{Discussion}

Millipede systematics is mainly based on male gonopods because they use to be species-specific (Bond et al. 2003). However, studies based on DNA have demonstrated that molecular divergence in different millipede groups may not reflect divergence in morphology-based identifications and may hide considerable variation (Bond \& Sierwald 2002; Bond et al. 2003; Adams et al. 2009; Mwabvu et al. 2013, 2015; Tinago et al. 2017). Although our relatively small taxon sampling, the phylogenetic analysis strongly recovers Sechelleptus as monophyletic and discriminates at least two or three different groups. Furthermore, the mean inter-specific distance values (14.9\% for COI and 5.1\% for $16 \mathrm{~S})$ were remarkably similar to previous studies that reported the presence of high genetic divergence among population of different spirostreptid species (Mwabvu et al. 2013, 2015), suggesting the existence of more than one species in those taxa. It is argued that high level of divergence between identified spirostreptid species may indicate that changes in genital morphology occur rather slowly relative to 


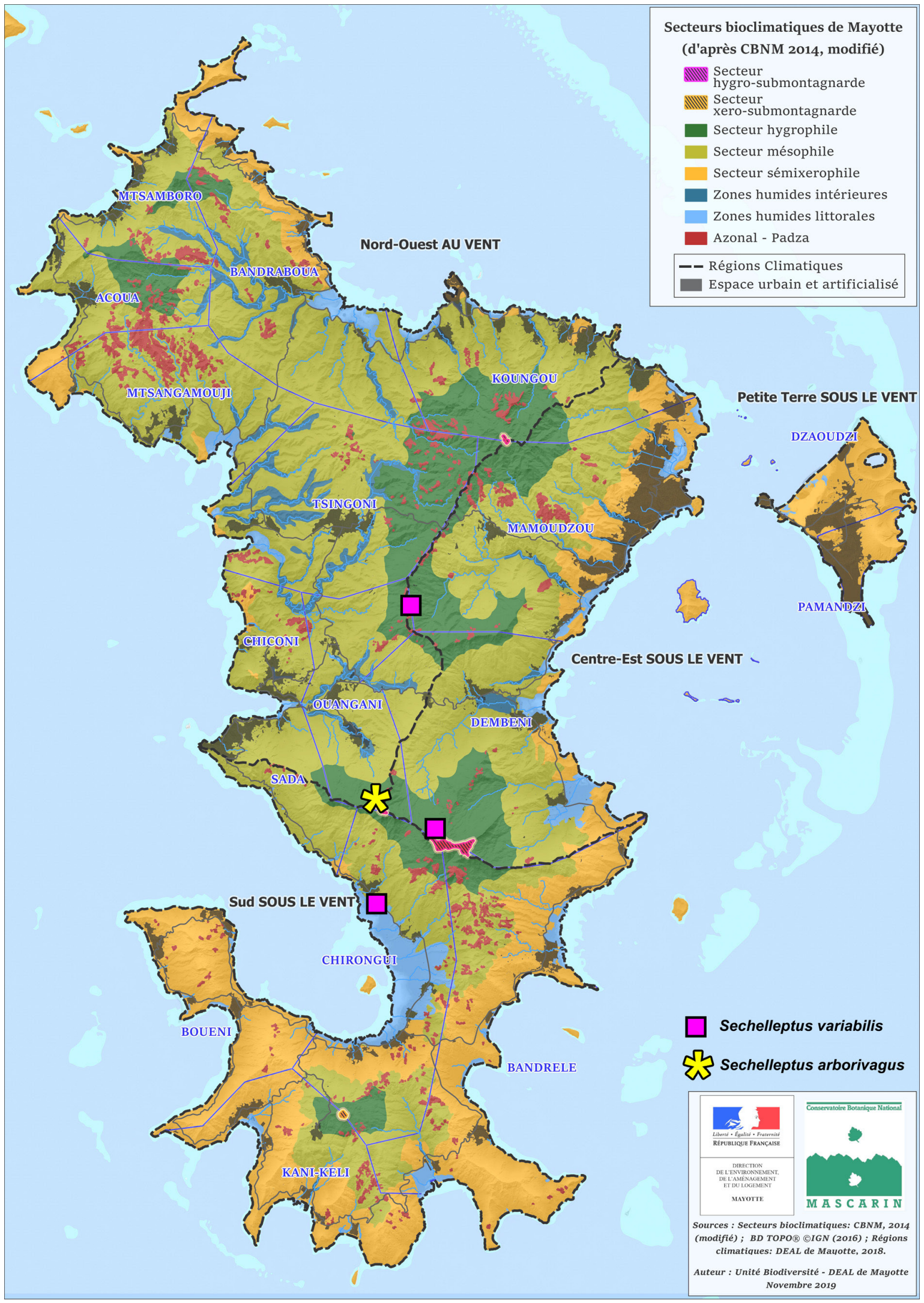

Fig. 8. Distribution of Sechelleptus arborivagus sp. nov and S. variabilis VandenSpiegel \& Golovatch, 2007 on Mayotte. 
the high rate of substitution in mitochondrial sequences (especially for COI), and may underestimate species diversity. This also appears to be the case among the different forms of Mayottan Sechelleptus, which also share strongly similar gonopods. At the first glance, the new species of Sechelleptus seems to be a giant form of $S$. variabilis. However, although only subtle morphological differences are observed within the gonopods, the comparatively large body size and the behavior of $S$. arborivagus sp. nov. are remarkable. These observations finally corroborate our molecular analyses that clearly show sufficient genetic difference between the different Sechelleptus species collected on Mayotte (22.6\% for COI and $6.6 \%$ for $16 \mathrm{~S}$ between $S$. arborivagus sp. nov. and S. variabilis).

The genetic analyses also suggest the presence of another different species, i.e., DU1, although its phylogenetic position remains unresolved. This unique specimen found at Mont Combani is a sub-adult female that could not allow a formal identification, but, judging from its general appearance, appears to be an intermediate from between the two Sechelleptus species collected on Mayotte. The genetic divergences, along with adaptations to arboreal life observed in the novel species, may indicate an "adaptive micro-radiation" on Mayotte Island or even the Comoros. However, the inclusion of more specimens, including adult males, in phylogenetic analyses is needed to test this hypothesis and evaluate the status of that putative new species.

\section{Acknowledgments}

This work was supported by the 'Ministère de la transition écologique et solidaire - France'. Present sampling was performed in the framework of the program "Acquisition de connaissances sur les myriapodes de Mayotte" (convention N ${ }^{\circ}$ 2019-003/DEAL/SEPR) organized by the DEAL at Mayotte. We are grateful to Antoine Rouillé for his help in the organization of the sampling and Miguel LamalfaDiaz who guided us on the Mt. Tchaourembo. We are grateful to Alain Reygel for the drawings and Dr Sergei Golovatch for his kind advice on an early draft.

\section{References}

Adams D.C., Berns C.M., Kozak K.H. \& Wiens J.J. 2009. Are rates of species diversification correlated with rates of morphological evolution? Proceedings of the Royal Society B 276 (1668): 2729-2738. https://doi.org/10.1098/rspb.2009.0543

Bond J.E. \& Sierwald P. 2002. Cryptic speciation in the Anadenobolus excisus millipede species complex on the Island of Jamaica. Evolution 56: 1123-1135. https://doi.org/10.1111/j.0014-3820.2002.tb01426.x

Bond J.E., Beamer B.A., Hedin M.C. \& Sierwald P. 2003. Gradual evolution of male genitalia in sibling species complex of millipedes (Diplopoda: Spirobolida: Rhinocricidae: Anadenobolus). Invertebrate Systematics 17: 711-717. https://doi.org/10.1071/IS03026

Castresana J. 2000. Selection of conserved blocks from multiple alignments for their use in phylogenetic analysis. Molecular Biology and Evolution 17: 540-552.

https://doi.org/10.1093/oxfordjournals.molbev.a026334

Desjardins M. 1835. Description d'un insecte myriapode du genre Julus. Annales de la Société entomologique de France Séries 1 4: 171-174.

Edgecombe G.D. \& Giribet G. 2004. Adding mitochondrial sequence data (16S rRNA and cytochrome c oxidase subunit I) to the phylogeny of centipedes (Myriapoda, Chilopoda): an analysis of morphology and four molecular loci. Journal of Zoological Systematics and Evolutionary Research 42: 89-134. https://doi.org/10.1111/j.1439-0469.2004.00245.x

Enghoff I.B. \& Enghoff H. 1976. Notes on myriapods observed and collected in Tanzania and Kenya during the summer 1974. Xeroxed report, Zoological Museum, University of Copenhagen, Copenhagen- 
Enghoff H., Hoffman R.L. \& Howell K.M. 2016. Checklist of the millipedes (Diplopoda) of Tanzania. Journal of East African Natural History 105 (1): 51-113. https://doi.org/10.2982/028.105.0103

Golovatch S.I. \& Korsós Z. 1992. Diplopoda collected by the Soviet zoological expedition to the Seychelles Islands in 1984. Acta Zoologica Hungarica 38: 1-31.

Hedin M.C. \& Maddison W.P. 2001. A combined molecular approach to phylogeny of the jumping spider subfamily Dendryphantinae (Araneae: Salticidae). Molecular Phylogenetics and Evolution 18: 386-403. https://doi.org/10.1006/mpev.2000.0883

Hoffman R.L. 2008. Two new genera of spirostreptid millipeds from central Africa, with a new terminology for male genitalia in the family Spirostreptidae (Diplopoda Spirostreptida). Tropical Zoology 21 (2): 167-186.

Hoffman R.L. \& Howell K.M. 1983. Dendrostreptus, a new genus for an arboreal Tanzanian milliped, with notes on related forms (Diplopoda: Spirostreptidae). Revue zoologique africaine 97 (3): 625-632.

Jeekel C.A.W. 1999. A new Sechelleptus from Madagascar, with a key to the species of the genus (Diplopoda - Spirostreptida). Myriapod Memoranda 1: 45-57.

Katoh K. \& Standley D.M. 2013. MAFFT Multiple Sequence Alignment Software Version 7: improvements in performance and usability. Molecular Biology and Evolution 30: 772-780.

https://doi.org/10.1093/molbev/mst010

Krabbe E. 1982. Systematik der Spirostreptidae (Diplopoda, Spirostreptomorpha). Abhandlungen und Verhandlungen des Naturwissenschaftlichen Vereins in Hamburg (N.F.) 24: 1-476.

Kumar S., Stecher G., Li M., Knyaz C., \& Tamura K. 2018. MEGA X: Molecular Evolutionary Genetics Analysis across computing platforms. Molecular Biology and Evolution 35: 1547-1549.

https://doi.org/10.1093/molbev/msy096

Lanfear R., Frandsen P.B., Wright A.M., Senfeld T. \& Calcott B. 2016. PartitionFinder 2: new methods for selecting partitioned models of evolution for molecular and morphological phylogenetic analyses. Molecular Biology and Evolution 34 (3): 772-773. https://doi.org/10.1093/molbev/msw260

Lartillot N., Lepage T. \& Blanquart S. 2009. PhyloBayes 3: a Bayesian software package for phylogenetic reconstruction and molecular dating. Bioinformatics 25 (17): 2286-2288.

https://doi.org/10.1093/bioinformatics/btp368

Lavrov D.V., Boore J.L. \& Brown W.M. 2002. Complete mtDNA sequences of two millipedes suggest a new model for mitochondrial gene rearrangements: duplication and nonrandom loss. Molecular Biology and Evolution 19 (2): 163-169. https://doi.org/10.1093/oxfordjournals.molbev.a004068

Maddison W.P. \& Maddison D.R. 2018. Mesquite: a modular system for evolutionary analysis. Version 3.5. Program and documentation available from the authors at http://www.mesquiteproject.org [accessed May 2018].

Mauriès J.-P. 1980. Contributions à l'étude de la faune terrestre des îles granitiques de l'archipel des Séchelles (Mission P.L.G. Benoit - J.J. Van Mol 1972). Myriapoda - Diplopoda. Revue zoologique africaine 94 (1): 138-168.

Miller M.A., Pfeiffer W. \& Schwartz T. 2010. Creating the CIPRES Science Gateway for inference of large phylogenetic trees. In: 2010 Gateway Computing Environments Workshop (GCE): 1-8.

https://doi.org/10.1109/GCE.2010.5676129

Mwabvu T., Lamb J., Slotow R., Hamer M. \& Barraclough D. 2013. Is millipede taxonomy based on gonopod morphology too inclusive? Observations on genetic variation and cryptic speciation in Bicoxidens flavicollis (Diplopoda: Spirostreptida: Spirostreptidae). African Invertebrates 54: 349-356. https://doi.org/10.5733/afin.054.0203 
Mwabvu T., Lamb J., Slotow R., Hamer M. \& Barraclough D. 2015. Do cytochrome c oxidase 1 gene sequences differentiate species of spirostreptid millipedes (Diplopoda: Spirostreptida: Spirostreptidae)? African Invertebrates 56: 651-661. https://doi.org/10.5733/afin.056.0311

Pimvichaia P., Enghoff H. \& Panha S. 2014. Molecular phylogeny of the Thyropygus allevatus group of giant millipedes and some closely related groups. Molecular Phylogenetics and Evolution 71: 170-183. https://doi.org/10.1016/j.ympev.2013.11.006

Ronquist F., Teslenko M., van der Mark P., Ayres D.L., Darling A., Höhna S., Larget B., Liu L., Suchard M.A. \& Huelsenbeck J.P. 2012. MRBAYES 3.2: efficient Bayesian phylogenetic inference and model selection across a large model space. Systematic Biology 61 (3): 539-542.

https://doi.org/10.1093/sysbio/sys029

Sierwald P. \& Spelda J. 2021. MilliBase. https://doi.org/10.14284/370

Simon C., Frati F., Beckenbach A., Crespi B., Liu H. \& Flook P. 1994. Evolution, weighting, and phylogenetic utility of mitochondrial gene sequences and a compilation of conserved polymerase chain reaction primers. Annals of the Entomological Society of America 87: 651-701.

https://doi.org/10.1093/aesa/87.6.651

Stecher G., Tamura K. \& Kumar S. 2020. Molecular Evolutionary Genetics Analysis (MEGA) for MacOS. Molecular Biology and Evolution 37 (4): 1237-1239. https://doi.org/10.1093/molbev/msz312

Sukumaran J. \& Holder M.T. 2010. DendroPy: a Python library for phylogenetic computing. Bioinformatics 26: 1569-1571. https://doi.org/10.1093/bioinformatics/btq228

Sukumaran J. \& Holder M.T. 2015. SumTrees: phylogenetic tree summarization. 4.0.0. Program and documentation available from the authors at https://github.com/jeetsukumaran/Dendrophy [accessed Mar. 2017].

Talavera G. \& Castresana J. 2007. Improvement of phylogenies after removing divergent and ambiguously aligned blocks from protein sequence alignments. Systematic Biology 56: 564-577.

https://doi.org/10.1080/10635150701472164

Tinago T., Mwabvu T. \& MacDonald A. 2017. Evidence of multiple divergent mitochondrial lineages within the southern African diplopod genus Bicoxidens Attems, 1928 (Spirostreptida). African Zoology 52 (4): 229-235. https://doi.org/10.1080/15627020.2017.1387504

VandenSpiegel D. 2001. Taitastreptus flavipes, a new genus and new species for an arboreal millipede from Kenya (Diplopoda, Spirostreptidae). Insect Systematics and Evolution 32 (4): 475-480.

https://doi.org/10.1163/187631201X00317

VandenSpiegel D. \& Golovatch S.I. 2007. The millipedes from the Comoros Islands (Myriapoda, Diplopoda). Journal of Afrotropical Zoology 3: 41-57.

Vink C.J., Thomas M.S., Paquin P., Hayash C.Y. \& Hedin M. 2005. The effects of preservatives and temperatures on arachnid DNA. Invertebrate Systematics 19 (2): 99-104.

https://doi.org/10.1071/IS04039

Zwickl DJ. 2006. Genetic algorithm approaches for the phylogenetic analysis of large biological sequence datasets under the maximum likelihood criterion. $\mathrm{PhD}$ thesis, The University of Texas at Austin, USA.

Manuscript received: 28 October 2020

Manuscript accepted: 12 April 2021

Published on: 16 June 2021 
Topic editor: Nesrine Akkari

Desk editor: Pepe Fernández

Printed versions of all papers are also deposited in the libraries of the institutes that are members of the EJT consortium: Muséum national d'histoire naturelle, Paris, France; Meise Botanic Garden, Belgium; Royal Museum for Central Africa, Tervuren, Belgium; Royal Belgian Institute of Natural Sciences, Brussels, Belgium; Natural History Museum of Denmark, Copenhagen, Denmark; Naturalis Biodiversity Center, Leiden, the Netherlands; Museo Nacional de Ciencias Naturales-CSIC, Madrid, Spain; Real Jardín Botánico de Madrid CSIC, Spain; Zoological Research Museum Alexander Koenig, Bonn, Germany; National Museum, Prague, Czech Republic.

\section{Appendices}

Appendix 1. List of primers used to amplify the COI and 16S rRNA markers.

\begin{tabular}{lllll}
\hline Marker & Primer name & Direction & Primer sequence & References \\
\hline COI & C1-J-1718-spider & F & 5'-GGNGGATTTGGAAATTGRTTRGTTCC-3' & Vink et al. (2005) \\
& C1-N-2568 & R & 5'-GCTACAACATAATAAGTATCATG-3' & Hedin \& Maddison (2001) \\
16S rRNA & LR-N-13398 (16Sar) & F & 5'-CGCCTGTTTAACAAAAACAT-3' & Simon et al. (1994) \\
& LR-J-12887 (16Sbr) & R & 5'-CCGGTCTGAACTCAGATCACGT-3' & Simon et al. (1994) \\
\hline
\end{tabular}




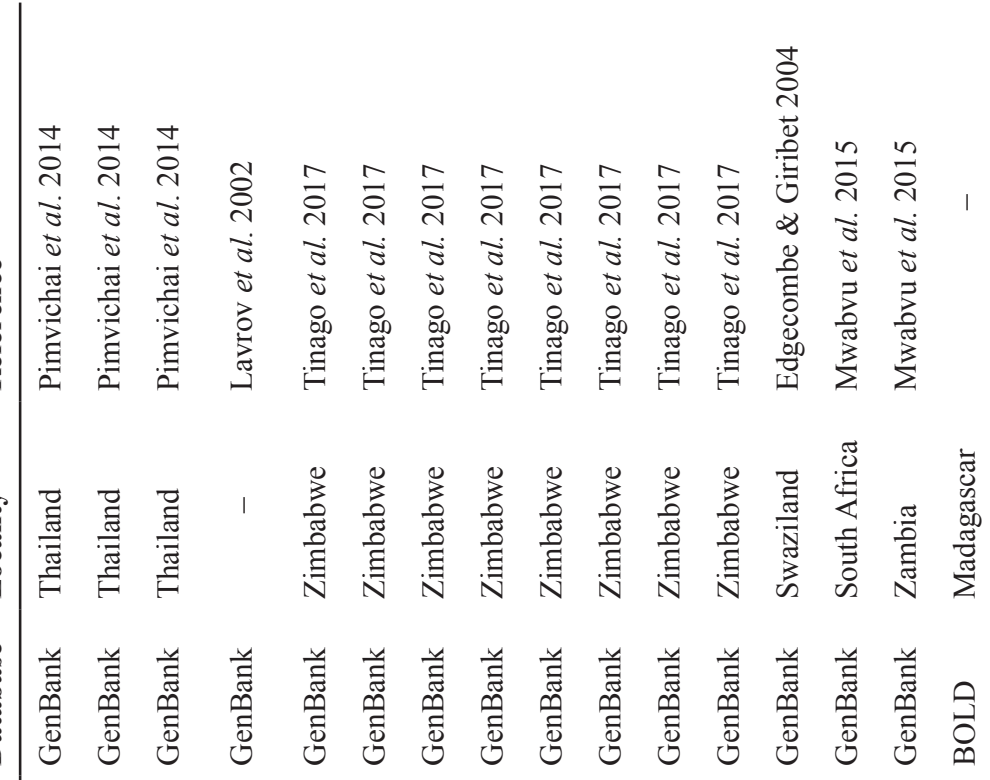

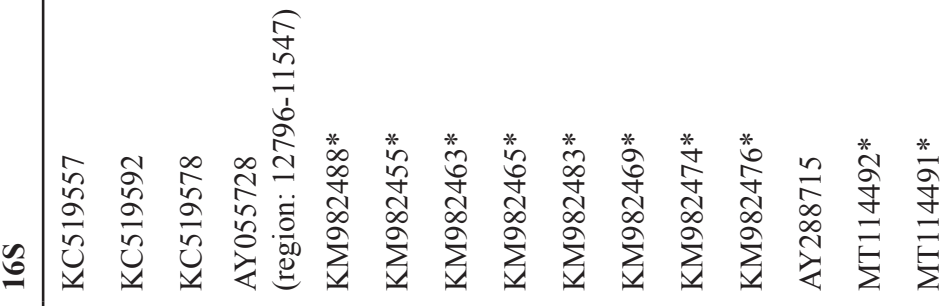

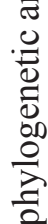

$\stackrel{2}{ \pm}$

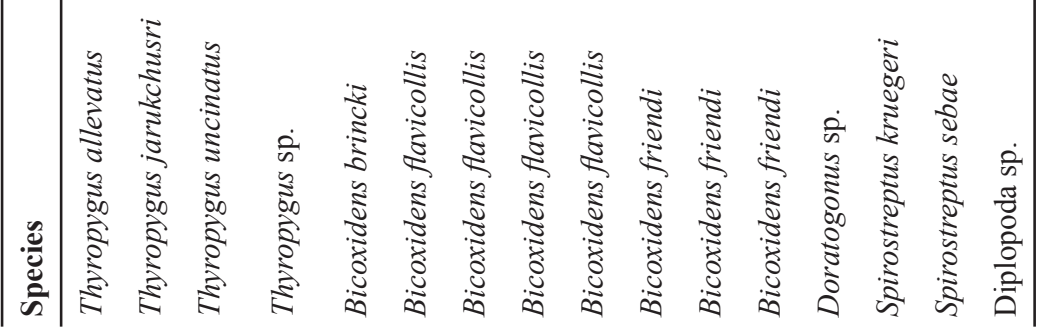


Appendix 3. Selection model estimated using PartitionFinder 2 (Lanfear et al. 2016) and based on one partition for 16S and three for COI (partitioned into single codon positions).

\section{Settings used}

alignment: ./COI_16S_GBLOCKS.phy

branchlengths: linked

models: JC, K80, SYM, F81, HKY, GTR, JC+G, K80+G, SYM+G, F81+G, HKY+G, GTR+G, JC+I, $\mathrm{K} 80+\mathrm{I}, \mathrm{SYM}+\mathrm{I}, \mathrm{F} 81+\mathrm{I}, \mathrm{HKY}+\mathrm{I}, \mathrm{GTR}+\mathrm{I}, \mathrm{JC}+\mathrm{I}+\mathrm{G}, \mathrm{K} 80+\mathrm{I}+\mathrm{G}, \mathrm{SYM}+\mathrm{I}+\mathrm{G}, \mathrm{F} 81+\mathrm{I}+\mathrm{G}, \mathrm{HKY}+\mathrm{I}+\mathrm{G}$, $\mathrm{GTR}+\mathrm{I}+\mathrm{G}$

model_selection: bic

search: greedy

\section{Best partitioning scheme}

Scheme Name: start scheme

Scheme lnL: -6422.05841064

Scheme BIC: 13324.1841399

Number of params: 69

Number of sites: 1051

Number of subsets: 4

\section{Subset | Best Model | \# sites | subset id | Partition names}

$1 \mid$ SYM+G $|187|$ 555f317e2b0e658f989fe7dcbaff9c08 |COI_1
$2 \mid$ F81 | 187|d014815e8c9674f9db22782683dcefb2 |COI_2
3| HKY+I+G | 187 | c8108630a819b5a05188ac5b43a5da04 |COI_3
4| HKY+I+G $490 \mid$ 855453fb15f46ffa6d1fc11c5a2c8afd | 16S

\section{Nexus formatted character sets used for GARLI}

begin sets;

charset Subset1 $=1-561 \backslash 3$;

charset Subset2 $=2-561 \backslash 3$;

charset Subset3 $=3-56113$;

charset Subset $4=562-1051$; end;

charpartition PartitionFinder = Group1:Subset1, Group2:Subset2, Group3:Subset3, Group4:Subset4;

\section{MrBayes block for partition definitions}

begin mrbayes;

charset Subset1 $=1-561 \backslash 3$;

charset Subset2 $=2-56113$;

charset Subset3 = 3-561\3;

charset Subset4 $=562-1051$;

partition PartitionFinder $=4:$ Subset1, Subset2, Subset3, Subset4;

set partition=PartitionFinder;

lset applyto=(1) $n s t=6$ rates=gamma;

prset applyto=(1) statefreqpr=fixed(equal);

lset applyto $=(2) \mathrm{nst}=1$;

lset applyto $=(3) \mathrm{nst}=2$ rates=invgamma;

lset applyto=(4) $n s t=2$ rates $=$ invgamma;

prset applyto $=($ all $)$ ratepr=variable; end;

unlink statefreq $=($ all $)$ revmat $=($ all $)$ shape $=($ all $)$ pinvar $=($ all $)$ tratio $=($ all $)$; 